Research Article

\section{Changes in intraocular pressure after ND-yag laser posterior capsulotomy}

\author{
Hashim Thiab Hassan* \\ Department of Ophthalmology, Alyarmouk Teaching Hospital, Baghdad, Iraq
}

\section{Abstract}

Background: The posterior capsule opacification (PCO) is also known as after cataract is a common complication after planned extra capsular cataract extraction (ECCE) with or without intraocular lens (IOL) implantation. The aim of this study was to evaluate the changes in intraocular pressure (IOP) after Nd-Yag laser posterior capsulotomy (LPC) for PCO. The Nd-Yag LPC is a safe and non- invasive procedure and can be performed as an outpatient procedure.

Patients \& methods: A total of one hundred eyes with symptomatic intact posterior capsule opacification (PCO) at Glaucoma Department of Alyarmouk Teaching Hospital fulfilling the inclusion criteria were enrolled in the study over a period of 6 months, 64 eyes were aphakic and 36 eyes were pseudophakic, the fellow eye was used as control. The base line pre-laser IOP was measured with the help of Goldmann Applanation Tonometer (GAT) and slit lamp examination before procedure. The pupils were dilated by using $1 \%$ tropicamide eye drops. Proparacaine eye drops were used 1-2 times for topical anesthesia, using Nd: YAG laser (VISULAS YAG III Carl Zeiss Meditec AG Germany), an opening of 3-4 mm was made in the posterior lens capsule, ensuring use of least possible energy. IOP was again assessed 1 hours, 24 hour and one week after the procedure.

Results: IOP was checked before laser, at one hour, 24 hour and one week after laser. There was statistically significant $(p<0.001)$ rise in IOP at one hour in both aphakic and pseudophakic groups from a mean of $12.54 \mathrm{mmHg}$ before laser to a mean of $20.79 \mathrm{mmHg}$ at one hour with an average of $8.35 \mathrm{mmHg}$ from baseline measurement. IOP at one hour rises from $2-5 \mathrm{mmHg}$ in 30 eyes $(30 \%),>5 \mathrm{mmHg}$ in 46 eyes $(46 \%)$ and $>10 \mathrm{mmHg}$ in 24 eyes (24\%). Every patient had an IOP at one hour equal to or greater than $22 \mathrm{mmHg}$ received anti-glaucoma drugs to control the rise in IOP. At 24 hours IOP decreased to a mean of $13.24 \mathrm{mmHg}$ in both groups. No distinction was made between the aphakic and the pseudophakic groups with regard to IOP changes. In all treated eyes, best corrected visual acuity (VA) was recorded before and at one week after $\mathrm{Nd}$ Yag laser application by Snellen's chart. After performing a central capsulotomy VA increased in all patients. In no eye was the post-laser VA lower than before laser treatment.

Conclusion: Photo-disruption with Nd-Yag laser is a safe and an effective method in management of PCO. However, there are several complications known to follow capsulotomy as significant rise in IOP and only if we can minimize their frequency or, better still, avoid them altogether, can we accept Nd-Yag LPC as a safe procedure in our effort to restore vision in cases of PCO.

\section{More Information \\ *Address for Correspondence: Dr. Hashim Thiab Hassan, Department of Ophthalmology, Alyarmouk Teaching Hospital, Baghdad, Iraq, Email: drhthophth@gmail.com}

Submitted: 18 November 2019

Approved: 19 May 2020

Published: 20 May 2020

How to cite this article: Hassan HT. Changes in intraocular pressure after ND-yag laser posterior capsulotomy. Int J Clin Exp Ophthalmol. 2020; 4: 021-030.

DOI: 10.29328/journal.ijceo.1001029

ORCiD: orcid.org/0000-0003-1116-9250

Copyright: @ 2020 Hassan HT. This is an open access article distributed under the Creative Commons Attribution License, which permits unrestricted use, distribution, and reproduction in any medium, provided the original work is properly cited.

Keywords: Cystoid macular edema (CME). Continuous wave (CW); Extra-capsular cataract extraction (ECCE); Intraocular lens (IOL); Intraocular pressure (IOP); Infrared (IR); Laser posterior capsulotomy (LPC); Millijoule (MJ); Micrometer (Mm); Millimeter ( $\mathrm{mm}$ ); Millimeter mercury $(\mathrm{mmHg})$; Neodymium-yttriumaluminum-garnet laser (Nd-Yag L); Number (No.). Nanometer (nm); Posterior capsule (PC); Posterior capsule opacification (PCO); Retinal detachment (RD); Standard of deviation (SD); Ultraviolet (UV)

\section{Check for updates}

OPEN ACCESS

\section{Introduction}

The Nd-Yag L has been developed in Europe since the mid1970s [10]. Today Nd-Yag LPC has become an established procedure for after cataract. Before the Nd-Yag L came into use, the capsulotomy was done by performing a small puncture with a needle knife or 27 gauge needle, either at the time of original operation or as a secondary procedure through the limbus in aphakic or through pars plana in pseudophakic. The Nd-Yag L preferred because it is non-invasive and infection cannot occur. The most important complication is a transient rise in IOP 1-3 hrs of Nd-Yag LPC [1]. Occasionally the pressure rise is high and can cause serious damage to the optic nerve, so that the IOP should be monitored and appropriate measures should be taken if necessary. Only if we can minimize its frequency or, better still, avoid it, altogether, can we accept Nd-Yag L as a safe procedure in our effort to restore vision. In otherwise normal eyes, a mild elevation of IOP is of no consequence because it usually resolves within 24 hour especially when the patient receives anti-glaucoma 
drugs before and after laser application. However in eyes with pre-existing glaucoma, the incidence of IOP elevation is higher and its duration is longer than in otherwise normal eyes. Some glaucomatous eyes may therefore require additional glaucoma therapy for several weeks following Nd-Yag LPC [3]. So monitoring is particularly important in the cases of glaucoma with optic nerve damage and field loss as these eyes are susceptible to small pressure rises for even a short period. A single rise to $40 \mathrm{mmHg}$ for a few hours can cause irreversible damage to the damaged optic nerve and lead to permanent visual loss or even blindness [1]. The purpose of this study is to evaluate the changes in IOP at 1 hour,24hour and 1 week after Nd-Yag LPC.

\section{Posterior capsule opacification}

Is the most common late complication of uncomplicated ECCE [3]. The older the patient at the time of surgery, the longer the period the patient was at risk for requiring LPC. This may be related to an age related decline in lenticular hyperplasia [19]. After-cataract has become a significant problem in that almost all pediatric patients and approximately half of adult patients develop an opaque posterior capsule after ECCE [5]. A number of methods may be used to avoid opacity of the posterior capsule. They include polishing and vacuum cleaning of the posterior capsule. Various lens designs such as a laser ridge and convex surface posteriorly have been used to form mechanical barriers to the formation of Elschnig`s pearls. Methods such as chemicals, cryo-application and irradiation have also been used. Despite these measures, at least 25\% still opacity with time [1]. InjecTable solution called lens epithelial necrosis factor (LENF) in tissue culture (human capsular flap) is tested to show the influence of cellular growth. The results showed that LENF is capable of damaging $100 \%$ of epithelial cells irreversibly if it is applied for 20 seconds or longer and thereby avoiding PCO [28].

\section{Types of posterior capsule opacification}

Primary opacification: Some soft, clear cortex sticks to the posterior capsule (residual posterior subcapsular plaque) [3]. This becomes partially absorbed by the action of the aqueous but often becomes shutoff by adhesion of the remains to posterior capsule [6]. This can be avoided by using hydro-dissection after anterior capsulotomy to hydro-dissect the posterior cortical lamella and performing a meticulous cortical clean-up.Routine polishing of the posterior capsule with a sandblasted cannula will remove the plaque and improve the immediate postoperative result [1]. Sometime the anterior and posterior parts of the lens capsule become apposed centrally while at the periphery residual cortex and proliferated epithelial cells persist so that a doughnut-shaped structure known as Sommering`s ring is formed [7].

Elschnig`s pearls: Are caused by proliferation of lens epithelium on to the posterior capsule at the site of apposition between remnants of anterior capsule and the posterior capsule[3] giving the posterior capsulea (fish eggs) appearance [6]. The proliferating epithelium may produce multiple layers, leading to frank opacification. Epithelial cells proliferate and instead of forming lens fibers, develop into large balloon-like cells which sometimes fill the pupillary aperture [6]. Each pearl appears to be one cell known as bladder cell (large globular cell) which stain homogenously with eosin and Congo red and sometime nucleated [7]. Polishing of the posterior capsule at the time of surgery does neither decrease the incidence nor delay the onset of this type of opacification. This is because the posterior capsule is only the scaffold for proliferating cells whose origin is beneath the anterior capsule. The most important preventive measure is to perform as wide an anterior capsulotomy as possible. The Elschnig`s pearls is the most frequently seen type of opacification and is related to the patient's age. It is extremely common in children and occurs in about $50 \%$ of adults after 3-5 years [3]. The pearls are best seen with retro-illumination. These PCO is thin and can be opened with minimum power with Nd-Yag L.

Fibrous membrane: Consists of lens epithelium which has undergone fibrous metaplasia, these cells of epithelium congregate at the site of apposition between the anterior capsule remnant and the posterior capsule and can extend to a variable extent towards the visual axis. In posterior capsule with thicker fibrotic opacities, more power and shots may be needed to open the capsule [1]. The edge of the anterior capsule in contact with posterior capsule frequently forms a dense fibrotic adhesion. This becomes more opaque with time but as the opacity spares the central part of the posterior capsule, it does not normally affect VA. However it can affect visualization of retina.

Inflammatory membrane: If the previous operation has been followed by iritis, exudate adhere to lens remnants and organize. This is found mainly in diabetics [6].

Wrinkling and folding of the posterior capsule without actual opacification: The proliferating cells from epithelium of anterior capsule my undergo myofibroblastic differentiation. Their contraction produces numerous tiny wrinkles in the posterior capsule, resulting in visual distortion $[6,7]$. Beside lens epithelium, pigmented cells and connective tissue elements may participate [7].

\section{Indication for treatment}

Opacity seen with slit-lamp either by oblique lighting or retro-illumination does not necessarily mean poor VA [1]. The decision whether capsular opacity is significant requires the consideration of three factors:

First, the slit-lamp appearance of opacification.

Second, a fall of VA of 2 lines or more with the Snellen`s chart.

Third, clinical evaluation of visual potential by measuring 
the macular potential and evaluation of the macula with indirect ophthalmoscope [1].

Indication for treatment are as follows:

\section{Diminished VA.}

2. Impaired visualization of the fundus for diagnostic or therapeutic purposes.

3. Monocular diplopia or sever glare caused by wrinkling of the posterior capsule [3].

\section{Nd-Yag Laser}

Photo-disrupter laser is the major class of ophthalmic lasers. It is a non-invasive method of performing posterior capsulotomy on an out-patient basis [1]. This solid state laser source emits an infra-red (IR) light invisible to the eye of 1064 $\mathrm{nm}$ wavelength. A red Helium-Neon (He-Ne) laser aiming beam is therefore incorporated into the instrument [4], is aligned through the same optical pathway in the slit-lamp to allow accurate aiming of the beam [1]. The He-Ne laser is a low power gas laser producing a red beam [4]. The tissue disruption occurs at the focal point of the two laser beams [1]. The Nd-Yag $\mathrm{L}$ is a powerful continuous wave(CW) laser which is usually used Q-switched when treating the eye. Neodymium $(\mathrm{Nd})$ ions produce the laser light and they are contained as impurity ions within an optically pure Yag crystal [4]. Solid crystals are usually pumped by incoherent light such as the Xenon arc flash lamp [29]. In this way a much higher concentration of active laser Nd ions can be achieved than in a gas laser medium [4]. Photo-disruption is a physical process known as optical breakdown, were by focused emitted laser energy of extreme intensity can be used to create such a strong electro-magnetic field that leads to molecular breakup. A strong local shock-wave results, which can be used in surgery to disrupt tissues [1]. If a large amount of energy is rapidly delivered into a tiny focal volume in a very short time, the constituent atoms of the target material will be ionized and disintegrate into a collection of electrons, ions and unionized atoms called a plasma at the focal point of Nd-Yag L with explosive expansion. This rapidly expands causing acoustic and shock waves which can disrupt tissue in the immediate neighborhood of the blast. The Q-switched Nd-Yag L is used in this way to disrupt posterior capsule [4]. A similar process occurs when lightning is followed by thunder in a storm and the atmosphere becomes ionized to a plasma state. Lightning occur as electrons rejoin their atoms. Thunder represents the resultant shock-wave created by this sudden energy release [1]. In Q-switched Nd-Yag L the duration of each laser pulse reduces to 10-20 nanoseconds [4], this allow fierce ionization of the target tissue in the eye with creation of a flash, then a shock-wave results in photo-disruption of the molecules [1]. Laser releases a giant pulses of energy, when this pulse is focused to a 15-20 Mm spot, so that the nearly instantaneous light pulse exceeds a critical level of energy density, optical breakdown occurs in which the temperature rises so high (about $10.000 \mathrm{C}$ ) at the point of focus, that electrons are stripped from atoms, resulting in a physical state known as plasma. This expands with momentary pressures as high as 10 kilobars exerting a cutting effect up on the ocular tissue [5]. Because the initial plasma size is so small, it has little total energy and produces little effect away from a point of focus [5]. The energy of shock-wave is quickly dissipated within 3-4 mm so that tissue disruption is very localized. This is an important consideration in preventing damage to an intraocular lenses (IOLs) or adjacent tissue [1]. Though a significant shock-wave is produced, studies on polyethylene membranes indicate that direct contact with plasma is required for cutting tissue [5]. The radiated energy of shock-wave absorbed by matter, temperature rises so high about $(10.000 \mathrm{C})$ and the biological and clinical effects are correspondingly intense. Such high temperature can be produced by concentrating energy in to a very small focal region with a lens. At high temperature roughly above $4000 \mathrm{C}$ all matters are transformed into gaseous state. At even higher temperature a portion or all of the atoms of this gas become ionized, releasing free electrons. Thus within the focal volume there are neutral atoms, ions, and free electrons all moving at high velocity and constantly colliding with each other. The collisions of the electrons with ions and unionized atoms produce electromagnetic radiation (i.e photons or light). This state of matter is referred to as a plasma or fourth state. The temperature of a plasma is a function of the kinetic energy of the particles it contains obviously, the higher the temperature (i.e the kinetic energy of the particles) the greater the mechanical, photo-disruptive effect in the focal spot [32]. Light from laser system can be delivered by a fiberoptic system built into slit-lamp microscope [1].

\section{Choice of Nd-Yag L}

The Nd-Yag L is equipped with a Q-switched fundamental mode, used in combination with the slit-lamp $12.5 \mathrm{X}$ magnification. As aiming beam 2 rotating $\mathrm{He}-\mathrm{Ne}$ laser are used. To minimize the amount of energy used and to avoid pitting of the optic, some Nd-Yag $\mathrm{L}$ is equipped with focusing system [1]. A delivery system where the Nd-Yag L beam can be focused a quarter or half a mm behind the point of visible focus is useful [1]. It avoid pitting the implant. It is important to have variable power, the power setting used is between 1-8 $\mathrm{mJ} /$ pulse. To avoid induced astigmatism, the aiming beam is adjusted so that it forms an angle of no more than $30^{\circ}$ with visual axis [3]. The laser beam has a cone angle of $16^{\circ}$. The cone angle of laser is small enough for the beam to focus on to the pupil and converge on to the capsule. It will also diverge sufficiently in the anterior vitreous so that there is minimal concentration of energy at any point nearer to the retina [1]. The key to safe and successful laser capsulotomy is accurate focusing and using the minimal amount of energy required to puncture the capsule with Q-switched laser [3], the laser has a computerized data printer. A special Abraham contact lens, which results in an increase in the laser cone angle from $16^{\circ}$ to $24^{\circ}$ and an extra magnification of 1.4 [17]. 


\section{The explanations for rise in IOP}

The mechanism for rise in IOP is unknown, many explanations have been put forward to explain the transient rise in IOP following Nd-Yag LPC it may be caused by the following:

1. It has been suggested that aqueous debris (released lens material) may become trapped in the juxta-trabecular meshwork or in the internal pores of Schlemm's canal, causing increased outflow resistance [12,16].

2. The shock-wave formed by the Nd-Yag L may induce:

A. A neuro-humoral reflex, which causes the release of neuropeptides which account for the rise in IOP. The breakdown of the blood aqueous barrier (BAB) and the release of inflammatory mediators are more likely during iridotomy than during capsulotomy, since iridotomy involves direct trauma to a highly vascular structure. Canning state [16], that if this is the predominant mechanism causing the IOP to rise, then the incidence and magnitude of the rise should be greater after iridotomy. In his study neither was observed. It is possible that prostaglandin (PG) release into the aqueous humor contributes to the rise in IOP following Nd-Yag L iridotomy. The formation of PGs in response to laser iridotomy has been suggested as the reason for the rise in IOP following $\mathrm{Nd}$-Yag L irradiation of the rabbit iris [16]. The role of PGs in IOP changes after Nd-Yag LPC is probably different from their effect after laser iridotomy [16] So there is no evidence that pre-treatment with topical indomethacin to decrease IOP rise after Nd-Yag LPC [16]. Krootila study demonstrates the release of calcitonin gene-related peptide (CGRP) into aqueous humor following $\mathrm{Nd}$-yag $\mathrm{L}$ anterior capsulotomy in rabbits, and suggest that CGRP is partly causing the increase in IOP and disruption of the BAB. He found that methylsergide attenuated the increase in the IOP and disruption of the BAB, following Nd-Yag L anterior capsulotomy [25].

B. Trabeculitis secondary to the radiating shock-wave [17].

3. Occasionally, the IOP rise can be due to pupillary block after the Nd-Yag LPC has displaced the anterior vitreous face $[1]$.

4. A rise of IOP after laser capsulotomy may be caused by a narrow angle glaucoma or these patients may be steroidresponders and it is possible to diagnose it by an ibopamine provocative test.

\section{Complication}

We prospectively studied 100 eyes with intact posterior capsule in 100 consecutive patients to determine the incidence of IOP changes after Nd-Yag LPC, and the following short-term complications occurred:

1. Transient IOP Rise in all cases, which will be the subject of this study and this is measured at one hour after treatment.
Immediately after laser there is no change in IOP, the IOP increases gradually till it reaches the maximum level 1-3 hour after laser.

2. IOL Damage (minor pitting) occurred in eyes with pseudophakia, IOL damage, could be minimized by using Nd-Yag L with focusing system [16] In all cases the slight IOL damage or minor pitting that occurred did not interfere with vision. A few small minute spots are accepTable. On the other hand larger pits or cracks indicating sever damage to the optics must be avoided. These pits of the optics, even if they are large, fortunately don't affect VA.

3. Bleeding during treatment, it occurs in cases where posterior synechiae exists and when accidently focusing on the pupil.

4. Vitreous Prolapse, vitreous prolapse should be avoided by making the capsulotomy as small as $2-3 \mathrm{~mm}$ in diameter [16].

5. Anterior Chamber Reaction was observed in all treated eyes and it was controlled by topical steroids.

In previous studies [2,26 and 30] the following long-term complications occurred:

1. Cystoid Macular Edema (CME).

2. Uveitis.

To prevent CME and uveitis they prescribe indomethacin eye drops for a period as long as 6 weeks, while during the first 2 weeks a combination of indomethacin and steroid eye drops is used [6]. There is some recent evidence that low dosage of acetazolamide i.e 1-2 Tablets daily work effectively in drying up the edema [1]. It is incidence appears to be less when capsulotomy is delayed for 6 months or more after ECCE as we done in our study [3]. By using laser flare cell meter (LFCM) monitoring of inflammation in patients undergoing laser treatment allowed optimal adjustment of anti-inflammatory therapy. Diclofenac eye drops, where sufficient to treat inflammation in all patients, undergoing Nd-Yag LPC [23].

3. Long-term IOP rise: In some cases trabeculectomy was needed to normalize a persistent rise in IOP.

4. Corneal Edema: Could be prevented by avoiding IOP rise and vitreous prolapse.

5. Retinal Break and Detachment: There is a statistically significant increase in the risk of RD or break in those patients who undergo Nd-Yag LPC after ECCE. Therefore, capsulotomy should be deferred until the patient visual impairment caused by PCO warrants the performance of capsulotomy [27]. In some cases vitreous prolapse occurred, probably due to a rather large capsulotomy and was followed later by a RD. A small capsulotomy, especially in aphakia, might minimize the occurrence of RD [16]. In patients with high myopia, it 
is wise to examine the retina with indirect ophthalmoscopy, before treatment. Nd-Yag LPC should be done very carefully in patients with high myopia, or in patients who have had RD surgery, using minimal application and energy [1], it is incidence appears to be less when capsulotomy is delayed for 1 year or more after ECCE [3].

6. Rubeosis Iridis in diabetic [2].

7. Corneal Endothelial Cell Loss [2].

8. Implanted IOL in capsular back subluxated or dislocated in to vitreous cavity may be due to post-laser capsular opening leads to lens dislocation, so that if a Nd-Yag LPC is necessary, it should not be performed before the $6^{\text {th }}$ post-operative month. It should also not exceed $4 \mathrm{~mm}$ in diameter [26].

\section{Patients and methods}

A total of one hundred eyes with symptomatic intact posterior capsule opacification (PCO) who had undergone planned ECCE with or without IOL implantation, without complication and undergone pimary Nd-Yag LPC at Glaucoma Department of Alyarmouk Teaching Hospital fulfilling the inclusion criteria were enrolled in the study over a period of 6 months. 64 eyes (64\%) were aphakic and 36 eyes (36\%) were pseudophakic. There were females $47(47 \%)$ and males 53 (53\%) a ratio of 1:1.2. 49 cases were right eye and 51 cases were left eye. The mean of age incidence was 54.5 years. The mean age of the aphakic group was 52 years while the the mean age of pseudophakic group was 57 years.

The following selection criteria were used.

*Patients older than 10 years.

*VA reduced not less than 6/60 due to PCO, cortical remnants and visual distortion due to wrinkling.

*More than 6 months interval between ECCE and Nd-Yag LPC.

*Only patients with posterior chamber IOL or without IOL.

*Tonometry on the fellow (control) eye is possible.

*No history of glaucoma or asthmatic bronchitis or any sort of intraocular surgery in both eyes other than ECCE.

*Clear cornea.

*No pre-existing uveitis.

*No systemic medication with beta-blocker or antiprostagladin agents.

*The patients excluded were those with pre-treatment applination tension below $8 \mathrm{mmHg}$ or above $21 \mathrm{mmHg}$.

VA was measured by Snellen's chart before measuring the IOP and after 1 week. IOP measured by using Goldmann applanation tonometer with topical anesthesia oxybuprocaine $0.4 \%$ eye drops and fluorescein strips immediately before laser treatment and at 1 hour,24 hour and 1 week after treatment in both eyes. The reported IOPs are the result of at least two measurements which were averaged. All the pupils were dilated with tropicamide $1 \%$ and phenylephrine $10 \%$ eye drops. The No. of laser pulses and the average energy per pulse were recorded at the time of treatment. Typical power used was 1-8 mJ / pulse. No. of pulses varied between 10-42.

The results were analyzed with:

*Student-t-test, it is a statistical test used to signify the difference between the mean of 2 groups.

*Paired-t-test, it is used to signify the difference between paired values of the same group.

${ }^{*} p$ - value, it is the probability which means if $p<0.05$ or $p$ $<0.001$ the result of significant difference is not due to chance.

$p$ - value: $p<0.05$ significant, the cut-off point between significant and not significant. $P>0.05$ not significant.

\section{Management}

We apply topical anesthetic oxybuprocaine $0.4 \%$ eye drop. The patient is seated on the slit lamp with the head properly fixed with stripe to minimize movement. Although Nd-Yag L can be delivered without contact lens, its use helps to focus the beam on to the posterior capsule, the lens enlarge the cone angle of beam at the focus and, because the diameter of the focus is smaller, facilitates laser puncture of the capsule,[3] furthermore it controls eye movement, separates the eyelids and magnify view [1]. We aimed at capsulotomy of 2-3 mm diameter is usually sufficient to improve VA with the minimal energy required to achieve optical breakdown to avoid vitreous prolapse. Some recommended that a capsulotomy should be equal to the pupil under scotopic conditions and should approximate that of undilated pupil. It can always be enlarged if the patient complains of being optically aware of the edge of the opening. Larger openings are necessary for adequate retinal examination or retinal photocoagulation. We start with approximately $1 \mathrm{~mJ}$. Adjust laser to give minimum power which will achieve effective cutting. Laser energy is more efficient when it is delivered perpendicular to a posterior capsule, obliquity of the beam on the eye should, therefore, be avoided. Focus dual He-Ne aiming beam slightly behind posterior surface of the capsule to avoid marking the lens, if focused too far posteriorly, the capsule will not be punctured, and then moved slowly anteriorly until the capsule is cut. This avoids damage to the IOL by the laser. Avoid application directly along the visual axis and start the treatment where there is adequate clearance. Begin treatment superiorly and proceed inferiorly, unzippering capsule. If necessary, perform cruciate incisions at 3 and 9 o'clock to increase the capsulotomy diameter. 
Post-operative Procedure and Follow up: We measure IOP at 1 hour post laser. Those patients with IOP less than $21 \mathrm{mmHg}$ receive no pressure-lowering medication. Patients with applanation tension $=>22-30 \mathrm{mmHg}$ were given topical beta-blocker (timolol $0.5 \%$ eye drops) twice a day through to the 24 hour post treatment visit. Acetazolamide (diamox 250 mg Tablet) twice a day was used when the rise in IOP was greater than $30 \mathrm{mmHg}$ in addition to beta-blocker. Recheck the IOP at 24 hour. Follow up in 1 week post laser by measure VA and IOP. All patients were routinely given steroid eye drops (dexamethasone $0.1 \%$ ) 4 times per day for 1 week to treat inflammation beginning after the first post-treatment tension measurement was taken.

\section{Results}

A total of 100 patients (100 eyes) were studied, 64 eyes (64\%) were aphakic and 36 eyes (36\%) were pseudophakic. The mean pre-operative IOP was $12.54 \mathrm{mmHg}$ in both groups, $11.96 \mathrm{mmHg}$ in aphakic group and 13.55 in pseudophakic group (Figures 1,2), (Tables 1-3 ). The distributions of pretreatment IOP in the two groups were significantly different ( $p<0.001$ ) (Table 4, Figures 1,2). At one hour after laser treatment, the mean IOP was $20.79 \mathrm{mmHg}$ in aphakic group (Tables 2,4, Figures 1,2 ) and $20.58 \mathrm{mmHg}$ in pseudophakic group (Tables 3,4, Figures 1,2 ) the IOP increased an average of $8.35 \mathrm{mmHg}$ in both groups ( $p<0.001)$ (Table 1, Figures 1,2$)$, $9.09 \mathrm{mmHg}$ in the aphakic group $(p<0.001)$ (Table 2, Figures $1,2)$, and an average of $7.08 \mathrm{mmHg}$ in pseudophakic group ( $p<$ 0.001 ) (Table 3, Figures 1,2). The difference between the two groups was statistically not significant $(p>0.8)$ (Table 4$)$.

The mean change in IOP from baseline levels, at one hour, 24 hour at one week, and the relationship between baseline level and one hour,24 hour and one week post laser in the aphakic and pseudophakic groups are shown in the (Table 4, Figures 1,2). Table 5 shows that IOPs changes at one hour from baseline of $2-5 \mathrm{mmHg},>5 \mathrm{mmHg}$ and $>10$ $\mathrm{mmHg}$ in total patients and in comparison between aphakic and pseudophakic groups, in 2-5 mmHg shows more in pseudophakic group and in $>5 \mathrm{mmHg}$ and $>10 \mathrm{mmHg}$ more in aphakic group. At 24 hour after laser, the mean IOP was

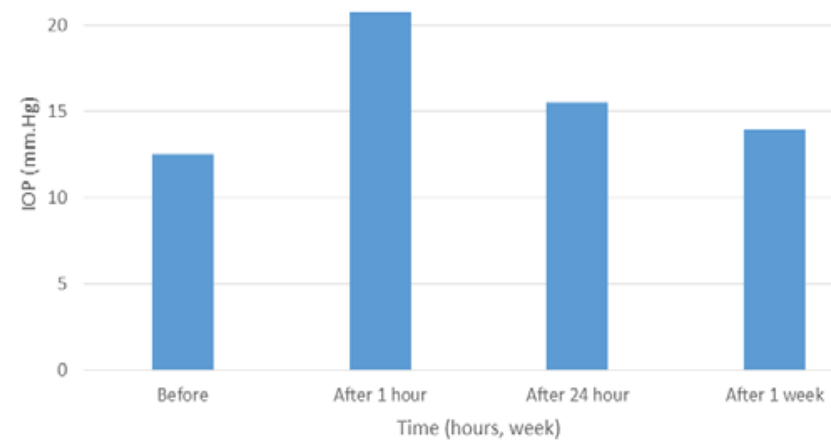

Figure 1: IOPs changes in total patients before and after laser.

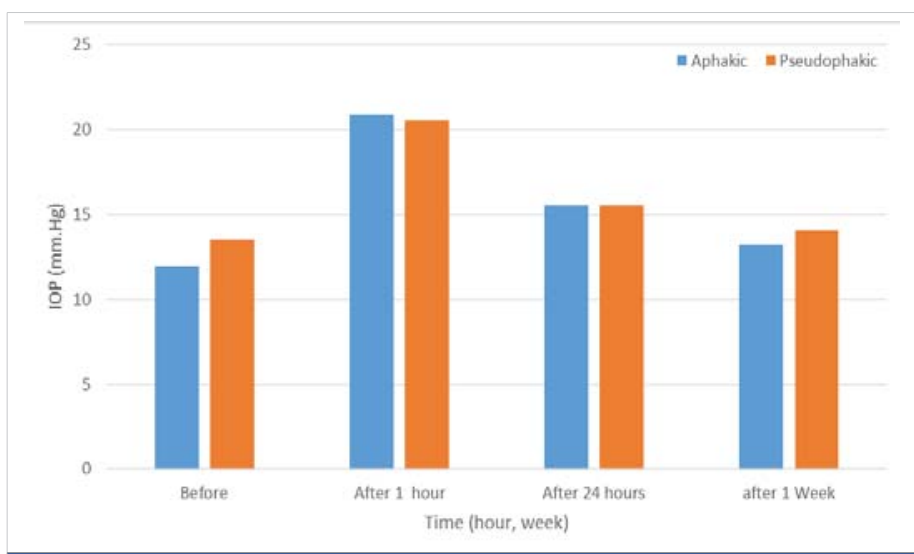

Figure 2: IOP change before and after laser in aphakic Vs pseudophakic patient.

\begin{tabular}{|c|c|c|c|c|c|}
\hline \multicolumn{5}{|c|}{ Table: IOPs $(\mathrm{mmHg})$ in total patients $(\mathrm{No} .100)$} \\
\hline Time & No. & Mean & S.D & Range & $p$ - value \\
\hline Before & 100 & 12.54 & 2.35 & Aug-20 & \\
\hline After 1 hour & 100 & 20.79 & 6.38 & Dec-40 & \\
\hline Difference & 100 & 8.35 & 5.52 & $0-26$ & $p<0.001$ \\
\hline After 24 hour & 100 & 15.54 & 3.02 & Aug-20 & \\
\hline Difference & 100 & 3 & 2.53 & $(-2)-10$ & $p<0.001$ \\
\hline After 1 week & 100 & 13.94 & 2.47 & Oct-20 & \\
\hline Difference & 100 & 1 & 1.49 & $(-2)-4$ & $p<0.001$ \\
\hline & & & & & \\
\hline
\end{tabular}

Table 2: IOPs (mmHg) in Aphakic Group (No = 64).

\begin{tabular}{|c|c|c|c|c|c|}
\hline Time & No. & Mean & SD & Range & $p$ - value \\
\hline Before & 64 & 11.96 & 2.23 & Aug-16 & \\
\hline After 1 hour & 64 & 20.9 & 6.5 & Dec-38 & \\
\hline Difference & 64 & 9.09 & 5.59 & $0-24$ & $p<0.001$ \\
\hline After 24 hour & 64 & 15.53 & 3.15 & Aug-20 & \\
\hline Difference & 64 & 3.56 & 2.46 & $(-2)-10$ & $p<0.001$ \\
\hline After 1 week & 64 & 13.25 & 2.45 & Oct-18 & \\
\hline Difference & 64 & 1.28 & 1.44 & $(-2)-4$ & $p<0.001$ \\
\hline
\end{tabular}

Table 3: IOPs $(\mathrm{mmHg})$ in pseudophakic Group (No = 36).

\begin{tabular}{|c|c|c|c|c|c|}
\hline Time & No. & Mean & SD & Range & $\boldsymbol{p}$ - value \\
\hline Before & 36 & 13.55 & 2.24 & Oct-20 & \\
\hline After 1 hour & 36 & 20.58 & 6.01 & Dec-40 & \\
\hline Difference & 36 & 7.08 & 5.22 & $0-26$ & $p<0.001$ \\
\hline After 24 hour & 36 & 15.55 & 2.33 & Oct-20 & \\
\hline Difference & 36 & 2 & 2.39 & 06-Jun & $p<0.001$ \\
\hline After 1 week & 36 & 14.05 & 2.46 & Oct-20 & \\
\hline Difference & 36 & 0.5 & 1.46 & $(-2)-4$ & $p<0.001$ \\
\hline
\end{tabular}

Table 4: Differences in Aphakic vs. Pseudophakic IOP rise after Nd-Yag LPC

\begin{tabular}{|c|c|c|c|c|c|}
\hline & & IOP mmHg & & & \\
\hline Variable & No. & Mean & SD & Range & $p$ - value \\
\hline Aphakic & 64 & 11.96 & 2.23 & Aug-16 & \\
\hline Psudophakic & 36 & 13.55 & 2.24 & Oct-20 & $p<0.001$ \\
\hline Total & 100 & 12.54 & 2.35 & Aug-20 & \\
\hline \multicolumn{6}{|l|}{ After 1 hour } \\
\hline Aphakic & 64 & 20.9 & 6.5 & $13-38$ & \\
\hline Psudophakic & 36 & 20.58 & 6 & Dec-40 & $p>0.08$ \\
\hline Total & 100 & 20.79 & 6.38 & Dec-40 & \\
\hline \multicolumn{6}{|l|}{ After 24 hour } \\
\hline Aphakic & 64 & 15.53 & 3.15 & Aug-20 & \\
\hline Psudophakic & 36 & 15.55 & 2.33 & Oct-20 & $p>0.8$ \\
\hline Total & 100 & 15.54 & 3.02 & Aug-20 & \\
\hline \multicolumn{6}{|l|}{ After 1 week } \\
\hline Aphakic & 64 & 13.25 & 2.45 & Oct-18 & \\
\hline Psudophakic & 36 & 14.05 & 2.46 & Oct-20 & $p>0.1$ \\
\hline
\end{tabular}


$15.54 \mathrm{mmHg}$ in both groups, $15.53 \mathrm{mmHg}$ in aphakic group and $15.55 \mathrm{mmHg}$ in pseudophakic group, the IOP was still elevated an average of $3.0 \mathrm{mmHg}$ above baseline levels in both groups ( $p<0.001$ ) (Table 1,Figures 1,2), $3.5 \mathrm{mmHg}$ above baseline levels in aphakic group $(p<0.001)$ (Table 2, Figures $1,2)$ ), $2.0 \mathrm{mmHg}$ above baseline levels in pseudophakic group $(p<0.001)$ (Table 3, Figures 1,2). The difference in IOP between aphakic and pseudophakic groups was statistically not significant at 24 hour after laser $(\mathrm{P}>0.8)$ (Table 4, Figures $1,2)$ ). At one week after laser, the mean IOP was $13.94 \mathrm{mmHg}$ in both groups, $13.25 \mathrm{mmHg}$ in aphakic group and 14.05 $\mathrm{mmHg}$ in pseudophakic group, the IOP, were still elevated an average of $1.0 \mathrm{mmHg}$ above baseline level in both groups ( $p<$ 0.001) (Table 1, Figures 1,2)),1.28 mmHg above baseline levels in aphakic group $(p<0.001)$ (Table 2, Figures 1,2)) and 0.5 $\mathrm{mmHg}$ above baseline levels in pseudophakic group $(p<0.05)$ (Table 3, Figures 1,2)). The difference in IOP between aphakic and pseudophakic eyes was statistically not significant at one week after laser $(p>0.1)$ (Table 4). The mean energy level was $6.4 \mathrm{~mJ}$ for both groups, $6.42 \mathrm{~mJ}$ in aphakic and $6.38 \mathrm{~mJ}$ in pseudophakic groups. The mean total energies applied to both groups were not significantly different. The relative effects of energy on the increase in IOP at one hour after laser not significant ( $p>0.2)$ (Table 7). The mean No. of pulses required to perform the capsulotomy was 26 pulse in both groups, 25.2 pulse in aphakic and 26.8 pulse in pseudophakic groups. The relative effects of No. of pulses on the rise in IOP at one hour after laser were not significant $(p>0.4)$ (Table 7). The relative effect of vitreous prolapse on the rise in IOP at one hour after laser was not significant $(p>0.6)$ (Table 8). The relative effect of bleeding on the rise in IOP at one hour after laser was not significant ( $p>0.1)$ (Table 8). The relatives effects of aphakia vs pseudophakia, patient age average energy, number of pulses, vitreous prolapse and bleeding on the rise in IOP at one hour after laser were studied by Student-t-test and Paired-t-test, of the factors described, neither one statistically significant. While VA was not the subject of this study, improvement in VA was, of course, the aim of the treatment. Table 9 and Figure 3 shows comparison between VA before and after one week post laser, this comparison shows significant difference between the 2 values. In no eye was the post laser VA lower than before laser treatment.

Table 5: Distribution of IOP at one hour after Nd-Yag LPC in Aphakic and Pseudophakic patients (No $=100)$.

\begin{tabular}{|c|c|c|c|c|c|c|}
\hline $\begin{array}{c}\text { Average IOP(mmHg) change } \\
\text { at 1 hour }\end{array}$ & $\begin{array}{c}\text { Total } \\
\text { No. }\end{array}$ & $\%$ & Aphakic & $\%$ & Pseudophakic & $\%$ \\
\hline 02-May & 30 & 30 & 16 & 25 & 14 & 39 \\
\hline$>5$ & 46 & 46 & 31 & 48.5 & 15 & 41.6 \\
\hline$>10$ & 24 & 24 & 17 & 26.5 & 7 & 19.4 \\
\hline Total & 100 & 100 & 64 & 100 & 36 & 100 \\
\hline
\end{tabular}

Table 6: No. of Pulses in Relation to IOP $(\mathrm{mmHg})$ at 1 hour post laser $(\mathrm{No}=100)$.

\begin{tabular}{|c|c|c|c|c|}
\hline No. of Pulses & No. of cases & IOP $(\mathrm{mmHg})$ & \\
\hline & & Mean & SD & $p$ - value \\
\hline$>20$ & 66 & 20.54 & 6.1 & $p>0.4$ \\
\hline$<=20$ & 34 & 21.32 & 6.3 & $p>0.4$ \\
\hline
\end{tabular}

Table 7: Power $(\mathrm{mJ})$ in Relation to IOP $(\mathrm{mmHg})$ at 1 hour post laser $(\mathrm{No}=100)$.

\begin{tabular}{|c|c|c|c|c|}
\hline Power(mJ) & No. of cases & IOP $(\mathbf{m m H g})$ & \multicolumn{1}{|c|}{} \\
\hline & & Mean & SD & $p$ - value \\
\hline$>4$ & 81 & 21.01 & 6.7 & $p>0.2$ \\
\hline$<=4$ & 19 & 19.68 & 4.3 & $p>0.2$ \\
\hline
\end{tabular}

Table 8: IOP changes at 1 hour post laser in relation to vitreous prolapse and bleeding (No = 100).

\begin{tabular}{|c|c|c|c|c|}
\hline Complication & No. of cases & IOP $(\mathbf{m m H g})$ & \\
\hline & & Mean & SD & $p$ - value \\
\hline (Negative) not occur & 71 & 20.59 & 7.58 & \\
\hline Vitreous prolapse & 24 & 21.12 & 3.72 & $p>0.6$ \\
\hline Bleeding & 5 & 23.5 & 3.41 & $p>0.1$ \\
\hline
\end{tabular}

Table 9: Visual Acuity Before and After one week Post laser (No = 100).

\begin{tabular}{|c|c|c|c|c|}
\hline VA & No. of eyes before & $\%$ & No. of eyes after 1 week & $\%$ \\
\hline 06-Jun & 2 & 2 & 5 & 5 \\
\hline 06-Sep & 6 & 6 & 20 & 20 \\
\hline 06-Dec & 8 & 8 & 20 & 20 \\
\hline Jun-18 & 18 & 18 & 14 & 14 \\
\hline Jun-24 & 12 & 12 & 23 & 23 \\
\hline Jun-36 & 20 & 20 & 18 & 18 \\
\hline Jun-60 & 34 & 34 & 0 & 0 \\
\hline Total & 100 & 100 & 100 & 100 \\
\hline
\end{tabular}

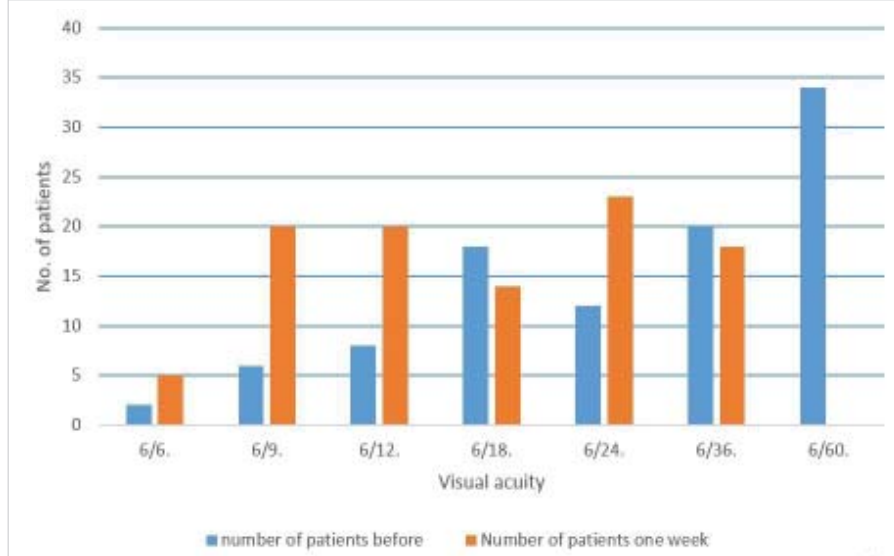

Figure 3: Visual acuity before and after one week post laser.

\section{Discussion}

Our study demonstrated a significant difference in IOP before treatment in aphakic and pseudophakic groups. This result does not go with the result of the study done in 1985 [12] by Kraff. At one hour after laser, the IOP increased significantly in both groups. This result goes with the results obtained in studies done in 1983 [11], 1985 [14], 1986 [16], 1987 [15], 1988 [17], 1990 [20] and 1993 [24] by Terry, Brown, Boen, Pham-Duy, Van-der, Zagorski and Ladas. The difference between the two groups was not statistically significant. This result goes with the results of study done in 1983 [11] by Terry, but does not go with the results of study done in 1985 [12] by Kraff. In one hour after laser the IOP rise from baseline levels $2-5 \mathrm{mmHg}$ in 30 eyes (30\%), > $5 \mathrm{mmHg}$ in 46 eyes (46\%) and $>10 \mathrm{mmHg}$ in 24 eyes (24\%) in both groups. These IOPs rise necessitate medically controlled by antiglaucoma drugs. Anterior chamber reaction was observed 
in all treated eyes and it was controlled by topical steroid. At 24 hour after laser, the mean IOP was $15.54 \mathrm{mmHg}$ an average of $3.0 \mathrm{mmHg}$ above baseline levels in both groups, the difference in IOP between both groups was statistically insignificant. At 1 week after treatment, the mean in IOP was 13.94 in both groups, an average of $1 \mathrm{mmHg}$ above baseline levels in both groups. The difference in IOP between both groups was statistically insignificant. This result goes with the results of study done in 1983 [11], by Terry, but does not go with the results of study done in 1985 [12]. by Kraff, in which the difference in IOP between aphakic and pseudophakic eyes was statistically significant at one week after laser. In our study we gave beta-blocker (timolol $0.5 \%$ ) eye drops twice a day when IOP rises more than $21 \mathrm{mmHg}$ at one hour post laser through to the 24 hour post laser treatment visit. Acetazolamide (diamox $250 \mathrm{mg}$ Tablet) twice a day was added when the rise in IOP was greater than $30 \mathrm{mmHg}$. The frequent occurrence of transient IOP rise following Nd-Yag LPC and the unpredictability of the degree of rise and the circumstances under which it will occur make prevention of IOP rise a major issue. In a study done in 1987 [15] by Pham-Duy found that topical indomethacin pretreatment had no positive effect on IOP and aqueous outflow, while beta-blocker and pilocarpine $2 \%$ prevented a post-operative elevation of IOP. In a study done in 1986 [16]. by Boen-Tan found that pretreatment with timolol $0.5 \%$ eye drops minimize IOP rise but does not give complete protection. The combination of timolol $0.5 \%$ eye drop with one Tablet of acetazolamide $250 \mathrm{mg}$ proves to be safe procedure for the prevention of IOP rise after Nd-Yag LPC, since both timolol and diamox are effective for about 12 hour, with this combination longer-term IOP rise will also be minimized. In a study done in 1993 [24], by Ladas found that pretreatment with a low dose of acetazolamide $1125 \mathrm{mg}$ daily) is highly effective in preventing IOP elevation following Nd-Yag LPC. Apraclonidine hydrochloride 1\% (iopidine 1\%) eye drop, it is a selective alpha-adrenergic agonist which helps to prevent a late post laser IOP elevation associated with Nd-Yag LPC by inhibiting aqueous secretion, is indicated to control or prevent elevation in IOP following Nd-Yag LPC, one drop instilled in the eye one hour before laser and one drop instilled in the same eye immediate upon completion of laser [3]. In a study done in 1997 by Ronald R. Holweger, shows that in eyes that operated up on by phacoemulsification technique show lack of communication between the aqueous and vitreous compartments with an intact capsulorhexis over the lens optic rim prevented obstruction of the trabecular meshwork by cellular debris or vitreous and this coupled with reduction in aqueous formation by iopidine eye drop before laser, prevented significant IOP elevation and routine IOP measurements 1 to 3 hours and one day after laser may not be necessary [32]. This type of technology in removal of cataract by phacoemulsification newly admitted to our country so not included in our study. In a study done in 1997 by Sanford Rakofsky, et al, shows that levobunolol $0.5 \%$ or timolol $0.5 \%$ administrated preoperatively and again in the evening after laser effectively blunted the IOP rise [33]. In a sudy done in 2000 by Janye Ge, et al, concluded that long term IOP is often elevated above pre-capsultomy baselines, especially in glaucoma patients or patients who experience a significant IOP increase within hours after the capsulotomy. Patients with glaucoma were more likely to require long term additional glaucoma medication than were non-glaucoma to require initial glaucoma therapy after the capsulotomy [34]. In a study done in 2004 by Christian Billote, et al. they concluded preventing PCO reduces the need for Nd-Yag PCL and its complication by improving cataract surgery techniques to decrease the incidence of complications related to Nd-Yag LPC [35]. In a study done in 2006 by Mustafa Unal, et al. they given brinzolamide $1 \%$ or apraclonidine $0.5 \%$ eye drops preoperatively to preventing IOP spike after Nd-Yag LPC [36]. In a study done in 2011 by Deepika Singhal, et al. they shows that use of topical brimonidine $0.2 \%$ one hour before laser has been proven effective to counteract the increase in IOP following Nd-Yag laser capsulotomy [37]. In a study done in 2014 by Pragati Garg, et al. concluded that a judicious control over energy use and post laser IOP monitoring can influence the trend of IOP rise in a positive manner. Whenever anticipated that $>60 \mathrm{~mJ}$ of laser energy is required as in higher grades PCO and younger age, prophylactically timolol $0.5 \%$ eye drop should be instilled before Nd-Yag LPC [38]. In a study done in 2016 by Ümit Çalli, et al. they concluded that use of brimonidine $0.2 \% 1$ hour before laser was demonstrated to prevent rise in IOP. In addition, there was no significant IOP increase as a result of fewer shots and low energy laser treatment [39].

In a study done in 2017 by Ch. M Subrahmanyaswara Rao, et al. they concluded that since significant pressure spikes occur, after laser procedure, it is important to put the patients on topical timolol maleate $0.5 \%$ drops 1 hour before laser and after capsulotomy Oral acetazolamide along with topical timolol can be used in patients who show rise of IOP uncontrollable with topical timolol alone [40] In a study done in 2017 by Bilal Murtaza, et al. they found that raised IOP was noted in $37(61.66 \%)$ out of total 60 cases and IOP remained unchanged in $20(33.33 \%)$ cases and use of high energy is associated with rise in IOP [38], while in our study all patients have rise in IOP after laser and the No. of laser pulses and the energy level are not probably related to the risk of elevation in IOP these differences may be due to use phacoemulsification technique in removal cataract in this study [41].

In comparison the result of these studies with our result they all coincide that the rise in IOP after Nd-Yag LPC is a major issue and must treated prophylactically to control the spike in IOP after laser. Nd:YAG laser capsulotomy is a safe method of restoring vision in patients with PCO. The results of Nd:YAG laser capsulotomy were comparable to those reported in literature.

The No. of laser pulses and the energy level are not 
probably related to the risk of elevation in IOP. These results go with those obtained in studies done in 1986 [16], and in 1985 [12], by Boen-Tan and kraff but not concide with result in study done in 2017 [41] by Bilal Murtaza, et al. in which high energy is associated with rise in IOP.

\section{Conclusion}

This study shows that Nd-Yag LPC is a safe and effective treatment for PCO after planned ECCE with or without IOL implant. The frequent occurrence of transient IOP rise following Nd-Yag LPC and the unpredictability of the degree of rise and circumstances under which it will occur, make prevention of IOP rise a major issue. Some patients when proceeding to do Nd-Yag LPC have an IOP more than normal levels, and have not been diagnosed before, have a shot rise in IOP after laser, also this happen in glaucomatous eyes, so it is advisable to measure IOP before do laser to all patients and should control the IOP before doing laser. The patients proceeded to do Nd-Yag LPC should receive antiglaucoma therapy to control or prevent elevations in IOP. Suitable time to do Nd-Yag LPC would be six months, after ECCE to minimize CME and RD. In general, minimum shots and total energy should be used. Capsulotomy $2-3 \mathrm{~mm}$ is usually sufficient to improve VA and minimize the possibility of vitrous prolapse. To avoid pitting the IOL, focus dual-He-Ne laser aiming beam slightly behind posterior surface of the posterior capsule. If the instrument equipped with focusing system it is better to use in posterior chamber IOL to avoid IOL pitting. The laser energy is more efficient when it is delivered perpendicular to the capsule. In uncooperative patients and thick opacified posterior capsule, using of contact lens is very effective.

\section{References}

1. Ian J. Constable. Arther Siew Ming Lim. Laser its clinical uses in eye diseases. Second edition. 1990.147.148.155.166-170.

2. Peter S. Hersh. Ophthalmic surgical procedures. First edition. 1988. 381-384.

3. Kanski JJ. Clinical ophthalmology. A systemic approach. Third edition 1995.304.305.

4. Andrew R. Elkington. Helena J. Frank. Clinical optics. 2nd edition. 1991. 18-20.

5. Daniel Vaughan. Taylor Asbury. Khalid F. Tabbara. Genera ophthalmology. 12th edition. 1989. 150.412.413.416.417

6. Stephen J.H Miller. Parson's diseases of the eye. 17th edition.1984.179.

7. Lucas DR. Greer's ocular pathology. 4th edition. 1989.301.309.

8. Patrick D. Trevor-Roper. The eye and its disorders. Second edition.1984.449.

9. Parr J. Introduction to ophthalmology. 3rd edition.1989.193.

10. Roper MJ. Hall. Stallard's eye surgery. 7th edition. 1989. 30-31.

11. Terry AC, Stark WJ, Maumenee AE, Fagadau W. Neodymium-Yag laser for posterior capsulotomy. Am JOphthalmol.1983; 96: 716-720. PubMed: https://www.ncbi.nlm.nih.gov/pubmed/6660258
12. Kraff MC, Sauders DR, Lieberman HL. Intraocular Pressure and the corneal endothelium after $\mathrm{Nd}$-Yag laser posterior capsulotomy. Relative effect of aphakia and pseudophakia. Arch Ophthalmol. 1985; 103: 511-514. PubMed: https://www.ncbi.nlm.nih.gov/pubmed/3985828

13. Wizeemann A, Jacobi-KW. Nd-Yag laser capsulotomy in intraocular lenses with reversed optics Klin Monatsbl Augenheilkd. 1984; 184: 175-179.

PubMed: https://www.ncbi.nlm.nih.gov/pmc/articles/PMC4346677/

14. Brown SV, Thomas JV, Belcher CD 3d, Simmons RJ. Effect of pilocarpine in treatment of intraocular pressure elevation following $\mathrm{Nd}$ Yag laser posterior capsulotomy. Ophthalmology. 1985; 98: 354-359. PubMed: https://www.ncbi.nlm.nih.gov/pubmed/3991123

15. Pham DT, Wollensak J, Beker U. Elevation of intraocular pressure following Nd-Yag laser capsulotomy. Pathogenesis and preventive therapy. Klin Monatsbl Augenheilkd. 1987; 191: 270-274.

PubMed: https://www.ncbi.nlm.nih.gov/pubmed/2891867

16. Boen-Tan TN, Stilma JS. Prevention of IOP-rise following Nd-Yag laser posterior capsulotomy with preoperative timolol eye drops and 1 Tablet acetazolamide 250mg systematically. Doc Ophthalmol. 1986; 64: 5967. PubMed: https://www.ncbi.nlm.nih.gov/pubmed/3582103

17. Van der Feltz van der Sloot D, Stilma JS, Boen-Tan TN, Bezemer PD. Prevention of IOP-rise following $\mathrm{Nd}$-Yag laser capsulotomy with topical timolol and indomethacin. Doc Ophthalmol. 1988; 70; 209-214. PubMed: https://www.ncbi.nlm.nih.gov/pubmed/3234187

18. Loh. RC. NdYag laser, photo-disruption and its clinical applications. Ann Acad Med Singapore. 1989; 18: 186-189.

PubMed: https://www.ncbi.nlm.nih.gov/pubmed/2751235

19. Maltzman BA, Haupt E, Notis C. Relationship between age at time of cataract extraction and time interval before capsulotomy for opacification. Ophthalmic Surg. 1989; 20: 321-324.

PubMed: https://www.ncbi.nlm.nih.gov/pubmed/2726145

20. Zagorski Z, Jaroszynski A, Grunwald W. Use of Nd-Yag laser in cataract extraction. Klin-Oczna. 1990; 92: 184-185.

21. Barbosa A, Hamard H, Ruellar YM. Effects and complications of $\mathrm{Nd}$ Yag laser posterior capsulotomy after ECCE and posterior chamber implantation. Bull Soc Ophthalmol. 1990; 90: 1576-1578.

PubMed: https://www.ncbi.nlm.nih.gov/pmc/articles/PMC4378868/

22. Albert DW, Wade EC, Parrish RK 2nd, Flynn HW Jr, Slomovic AR, et al. A prospective study of angiographic cystoid macular edema one year after vNd-Yag posterior capsulotomy. Ann Ophthalmol. 1990; 22:139-143.

PubMed: https://www.ncbi.nlm.nih.gov/pubmed/2350122

23. Ladas ID, Pavlopoulos GP, Kokolakis SN, Theodossiadis GP. Prophylactic use of acetazolamide to prevent IOP elevation following $\mathrm{Nd}$ Yag laser posterior capsulotomy. Br J Ophthalmol.1990; 77: 136-138. PubMed: https://www.ncbi.nlm.nih.gov/pubmed/8457502

24. Krootila K, Oksala O, von Dickhoff K, Wimalawansa SJ, Maclntyre I, et al. Ocular irritative response to $\mathrm{Nd}$-Yag laser capsulotomy in rabbits: release of calcitonin gene-related peptide and effects of methylsergide. Curr Ege Res.1992; 11: 307-314.

PubMed: https://www.ncbi.nlm.nih.gov/pubmed/1326426

25. Saad M, Dempler U. Risk of dislocation and cataract formation in 240 IO-GEL lenses 4 years experiences. Ophthalmolopy. 1992; 89: 338-341.

26. Javitt JC, Tielsch JM, Canner JK, Kolb MM, Sommer A, et al. National outcomes of cataract extraction. Increased risk of retinal complication associated with $\mathrm{Nd}$-Yag laser capsulotomy. The cataract patients outcomes research team. Ophthalmology. 1992; 99: 1989-1997. discussing 1497-8.

PubMed: https://www.ncbi.nlm.nih.gov/pubmed/1454313 
27. Hunold W, Wirtz M, Kreiner C, Greite JH, Kaden P. Lens epithelium necrosis factor for prevention lens opacity. Fortschr-Ophthalmol.1991; 88: 386-389.

PubMed: https://www.ncbi.nlm.nih.gov/pubmed/1786927

28. O'shea DC, Callen WR, Rhodes WT. Introduction to laser and their application. Optics, Refraction and contact lenses. Ame Academy Ophthalmol. 1994-1995.43.

29. Aron-Rosa Ds Aron JJ and Cohn HC. Use of pulsed picosecond Nd-Yag laser in 6664 cases. Ame Intra-Ocular implant Soc J. 1984; 0:35-39.

30. Fram Francus A, Lesperance JR. Ophthalmic laser. 1989; 2: 781.

31. Holweger RR, Marefat B. Intraocular pressure change after $\mathrm{Nd}-\mathrm{Yag}$ capsulotomy; J Cataract Refract Surg. 1997; 23: 115-121.

PubMed: https://www.ncbi.nlm.nih.gov/pubmed/9100118

32. Rakofsky S, Koch DD, Faulkner JD, Terry SA, Mandell Al, et al Levobunolol $0.5 \%$ and timolol $0.5 \%$ to prevent intraocular pressure elevation after Nd-Yag laser posterior capsulotomy. J Catract Refract Surg. 23: 1075-1080.

PubMed: https://www.ncbi.nlm.nih.gov/pubmed/9379380

33. Ge J, Wand M, Chiang R, Paranhos A, Shields MB. Long-term effect of Nd:YAG laser posterior capsulotomy on intraocular pressure. Arch Ophthalmol. 2000; 118: 1334-1337.

PubMed: https://www.ncbi.nlm.nih.gov/pubmed/11030814

34. Christian Biollotte MD. J Cataract Refract Surg. 2004; 30: 2964-2071.
35. Unal M, Yücel I, Akar Y. Brinzolamide 1\% versus apraclonidine $0.5 \%$ to prevent intraocular pressure elevation after neodymium:YAG laser posterior capsulotomy. J Cataract Refract Surg. 2006; 32: 1499-1502. PubMed: https://www.ncbi.nlm.nih.gov/pubmed/16931262

36. Singhal D, Desai R, Desai S, Shastri M, Saxena D. Use of topical brimonidine $0.2 \%$ to prevent intraocular pressure elevation following $\mathrm{Nd}-\mathrm{Yag}$ laser posterior capsulotomy. J Pharmacol Pharmacother. 2011; 2: 104-106.

PubMed: https://www.ncbi.nlm.nih.gov/pmc/articles/PMC3127336/

37. Garg P, Malhotra R, Singh L, Agarwal K, Garg A. Role of prophylactic use of timolol $0.5 \%$ in preventing rise of intraocular pressure post Nd-Yag laser posterior capsulotomy: Negrian J Ophthalmol. 2014; 2: 20-23.

38. Çalli U, Akmaz B, Ayyildiz T, Oral AY, Bulut MN, et al; The Effect of Prophylactic Topical Brimonidine on Intraocular Pressure After Nd: YAG Laser Posterior Capsulotomy: J Kartal TR. 2016; 27: 107-110.

39. Rao CMS, Satyasrinivas V, Muralikrishna V, Anuhya Y, Barua K. Clinical Study of Visual Outcome and Intraocular Pressure Changes Following Neodymium-doped Yttrium Aluminum Garnet Laser Capsulotomy in Post-operative Cataract Patients with Posterior Capsule Opacification. Int J Scientific Study. 2017; 5: 76-82.

40. Murtaza B, Hussain AW, Haq AU, Hameed A. Changes in intraocular pressure following high energy $\mathrm{Nd}-$ Yag laser posterior capsulotomy; Pak Armed Forces Med J. 2018; 68: 872-875. 